\title{
Redimensionar las Relaciones Públicas: en busca de un constructo teórico que optimice la dinámica comunicacional entre las realidades sociales y empresariales
}

Recibido: 28 de enero de 2012

Aceptado: 31 de julio de 2012

Publicado: 31 de octubre de 2012

\author{
Amybel Sánchez de Walther \\ amybelsanchez.usmp@gmail.com \\ Universidad de San Martín de Porres (Perú)
}

\begin{abstract}
Resumen: No hay duda que en un mercado globalizado (altamente competitivo y exigente, donde se busca la excelencia, la honestidad y la creatividad empresarial) las Relaciones Públicas deben erigirse como una ciencia social multidisciplinaria y flexible, dirigida no sólo a la consecución de los objetivos corporativos, sino también a seguir con detenimiento el desenvolvimiento de las comunidades campesinas, los diversos gremios, sindicatos y ONG; instituciones, autoridades estatales y los colectivos ciudadanos en general.
\end{abstract}

Sólo un profundo entendimiento de los fines holísticos de las Relaciones Públicas (compenetrados con el progreso y bienestar del país) y la comprensión empática de las posiciones y exigencias de los distintos agentes sociales permitirán la legitimación de las actividades extractivas en escenarios conflictivos (tal como se puede observar actualmente en el Perú) y el consecuente fortalecimiento del dinamismo financiero del país; el aumento de los índices de empleo, la reducción de la pobreza extrema; y la creación de lazos solidarios entre la clase empresarial y la sociedad: ambas reunidas en una labor mancomunada y cívica.

Palabras clave: Relaciones Públicas, programas estratégicos de comunicación, comunicación organizacional, comunicación interna y externa, cultura organizacional, plan de crisis, responsabilidad social corporativa, reputación, grupos de interés.

Abstract: There is no doubt that in a globalized market (highly competitive and demanding, which seeks excellence, honesty and business creativity) Public Relations must be constructed as a social science, multidisciplinary and flexible, directed not only to the attainment of corporate objectives, but also to follow closely the development of rural 
communities, the various guilds, unions and NGOs; institutions, State authorities and citizen groups in general.

Only a deep understanding of the purpose of Public Relations holistic (committed to the progress and well-being of the country) and the empathic comprehension of positions and demands of the various social actors will legitimize extractive activities in conflict scenarios (such as can currently be seen in Peru) and the consequent strengthening of the financial dynamics of the country; the increase in rates of employment, the reduction of extreme poverty; and the creation of solidarity links between business class and society: both gathered in a joint and civic work.

Key words: Public Relations, Strategic Program of Communication, Communications in Organizations, Internal and External Communication, Organizational Culture, Crisis Plan, Corporate Social Responsibility, Reputation, Stakeholders.

\section{Introducción}

La naturaleza multilateral e interactiva que caracterizan actualmente las relaciones entre las organizaciones empresariales y sus diversos públicos es consecuencia de la nueva dinámica económica predominante en el globo: el empresariado comienza a mostrar una decidida apertura a la aplicación de los principios de las Relaciones Públicas en mérito al nuevo rol que adoptan en la sociedad, ya que la actividad privada canaliza la mayoría de las fuerzas de producción y de generación de riqueza en la mayoría de los países, sobre todo en aquellos que cuentan con sistemas democráticos estables.

El crecimiento y ampliación del sector empresarial está generando un altísimo grado de competitividad, que obliga a muchas empresas encontrar nuevas vías para alcanzar la excelencia en el servicio, la eficiencia en la gestión y la idoneidad de los bienes producidos. Precisamente en ese punto, las Relaciones Públicas surgen como una clave vital para la planificación, la prevención y la creatividad comunicativa: no sólo se encargará de difundir las cualidades positivas de la corporación, sino de subrayar otros valores, tales como la reputación y la responsabilidad social, altamente reconocidos en el mercado mundial y sobre todo en el peruano, donde se cierne últimamente un clima de incertidumbre, recelo y desconfianza hacia las actividades extractivas.

En los siguientes apartados se examinarán diferentes aspectos de las Relaciones Públicas contemporáneas: su esencia multidisciplinaria, su papel en el plano corporativo y en la alta gerencia; su incidencia en contextos de crisis y la trascendencia de los proyectos de Responsabilidad Social; así como su intrínseca ligazón con las nuevas tecnologías de la información y la comunicación (NTIC).

\section{Relaciones Públicas: consolidando vías de diálogo}

En virtud de mantener el constante crecimiento y madurez de esta disciplina en nuestro país, es necesario redefinirla, logrando que la teoría y los conceptos en torno a ella estén más 
cercanos con las nuevas tendencias profesionales y académicas que están caracterizando su labor en el resto del mundo: unas Relaciones Públicas atentas a las exigencias y reacciones del mercado para convertirse en un interlocutor confiable y equilibrado entre las organizaciones y sus públicos ${ }^{1}$.

De esta manera, se lograría respetar las tareas que la encaminan a la excelencia profesional, ética y académica, evitándose confusiones terminológicas que la vuelven ambigua, así como la vulneración sistemática de las RR. PP. por la profusión de empíricos y la incidencia de estereotipos negativos, los cuales la suelen aproximar a un mero departamento de protocolo y ceremonial corporativa.

Para Martín Martín (2004: 149), los mensajes que elabora el relacionista público nacen dentro del ámbito empresarial, conformando un "conjunto de actividades y programas de comunicación efectuados por cualquier organización para crear y mantener buenas relaciones con sus diferentes públicos externos y proyectar ante ellos una imagen favorable".

En todo caso, los enfoques y alcances de estos mensajes deben estar diseñados de tal forma que promuevan la confluencia y concertación de diversos intereses sociales (referidos a los contextos comunitarios, locales o regionales), así como gubernamentales y corporativos. En ese sentido, Noguero (1999: 469) sostiene que las Relaciones Públicas "segmenta (de forma un tanto tradicional y en principio) a los sujetos receptores de las relaciones en dos grandes bloques: los públicos internos, que a su vez se estructura su clasificación de acuerdo con el tipo de organización específica; y los públicos externos que, en no pocas ocasiones, son concurrentes con las de otras organizaciones o instituciones".

Harrison (2002: 2) explica que las Relaciones Públicas “son el arte y la ciencia social consistentes en analizar tendencias, predecir sus consecuencias, asesorar a los líderes de la organización y poner en marcha los programas de acción planificados que servirían tanto a la organización como al interés del público". Una adecuada ejecución de esta disciplina estaría reflejada en "el esfuerzo planificado y sostenido por establecer y mantener la buena voluntad y la comprensión entre una organización y sus públicos”.

La misma autora (2002: 3) enfatiza que la meta concreta de esa labor es la reputación: "el resultado de lo que uno hace, lo que uno dice y lo que los demás dicen sobre uno. La práctica de las Relaciones Públicas es la disciplina que se ocupa de mantener la reputación, con el fin de lograr la comprensión y el respaldo, y de influir sobre la opinión y el comportamiento. Se trata de un esfuerzo planificado y sostenido por establecer y mantener la buena voluntad y la comprensión mutua entre una organización y sus públicos".

Entre los componentes esenciales de las RR. PP., Grunig y Hunt (2000: 59) enumeran "la definición de los públicos", "la investigación, la asesoría a la dirección" y "la redacción para los públicos". No obstante, apuntalan que algunas organizaciones no suelen emplear todos esos elementos y otras "simplemente no han pensado lo suficiente en las Relaciones Públicas como para saber qué podrían hacer con la función”.

1 Conjunto de ciudadanos, grupos u organizaciones que se encuentran en términos de correspondencia mutua directa o indirecta; interna o externa; y por tanto reciben el impacto endógeno y las consecuentes influencias exógenas del contexto. 
Figura 1: lineamientos generales de las Relaciones Públicas.

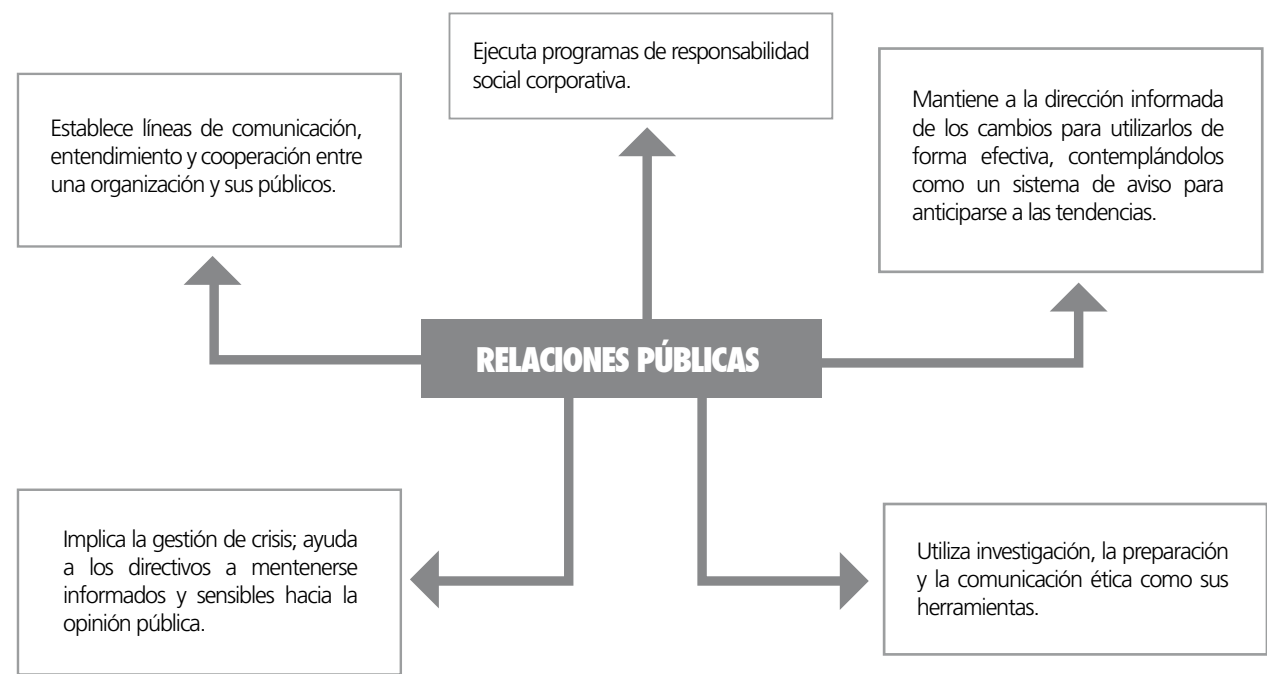

Fuente: elaboración propia basada en Harlow.

Tras esta breve radiografía conceptual, se puede determinar que las RR. PP. conforman una plataforma dialogante y tolerante que ayuda a integrar los objetivos de las organizaciones con los de sus públicos mediante la aplicación de estrategias comunicacionales que aseguren el intercambio bidireccional de información (feedback). Engloba una serie de actividades que, entre otras cosas, persigue maximizar el acuerdo entre las organizaciones y sus públicos (ya sean estos internos o externos) mediante el uso de estrategias y tácticas científicas de persuasión.

Las actividades y procedimientos de las Relaciones Públicas están intrínsecamente enlazados que con la realidad social: prestan ayuda a la comunidad a través de los programas de responsabilidad social y establece un contacto diario con la ciudadanía a fin de informarla y resolver inquietudes. Estos vínculos no solamente permiten que las organizaciones optimicen la relación con sus públicos, sino que enriquecen al propio relacionista que, en muchos casos, hacen suyos los anhelos de la comunidad.

No hay duda que las Relaciones Públicas tienen su fundamento en la capacidad natural del ser humano para la comunicación. Después de todo, el mutuo conocimiento y comprensión no es un requisito para establecer el acto comunicativo. Más bien, es consecuencia directa de este. Por ese motivo, en este artículo se insiste en la capacidad dialogante y abocada a la administración de controversias que posee las RR. PP., pese a que muchas expresiones ${ }^{2}$ han querido oscurecer el significado de esta disciplina.

2 La diversificación terminológica aludida ha formado dos corrientes bien delimitadas. En primer lugar, una caracterizada por su visión "marketera" y "economicista" de las RR. PP., subrayándose más el papel de la empresa ("Relaciones corporativas", "Relaciones institucionales", "Comunicación organizacional"). En segundo lugar, otra muy ligada a la publicidad y los procesos del branding ("Imagen institucional", "Imagen corporativa") que sólo privilegian las cualidades diferenciales y el "prestigio" de la marca. 
En todo caso, estos intentos de simplificación contrastan con la amplitud semántica de las RR. PP. Por un lado, el término "relación" (del latín refero) designa el conocimiento, el encuentro y la correspondencia fluida que debe existir entre las partes. Así, se asume que la profesión del relacionista surge de la necesidad de resolver conflictos. Por otro lado, lo "público" atiende diferentes conjuntos y colectivos de ciudadanos.

Con esta concepción terminológica se puede vislumbrar claramente la misión de esta especialidad, la cual no sólo intenta conocer las inquietudes de sus públicos o resolver conflictos sociales determinados, sino impulsar la productividad, el progreso y el bienestar de la población.

\section{Desarrollo y ejecución de las Relaciones Públicas}

No hay duda que el desenvolvimiento de esta disciplina debe contar con una orientación ética y responsable, sobre todo porque tiene a su cargo el contacto (constante y directo) con diversos grupos sociales, sobre todo en un escenario multicultural como el peruano. Empero, el carácter connatural de la profesión (que reside en el hecho de tener sus fundamentos en la capacidad natural del ser humano para la comunicación) trae consigo un obstáculo para el desarrollo mismo de las RR. PP.; toda vez que permite el ingreso a la actividad de personas que no cuentan con la preparación requerida para el progreso de la profesión.

La presencia de personas sin formación puede ser un óbice ${ }^{3}$, puesto que no poseen la red de conceptos que permiten al relacionista profesional cuidar los aspectos éticos en el manejo de la información o llevar una base de datos que, en cualquier momento contingente, puede ser interpretada o reinterpretada con el fin de solucionar un problema coyuntural de la manera más rápida y eficiente.

En el Perú, el fenómeno del empirismo en esta disciplina comunicacional se habría originado, décadas atrás, esencialmente por la ausencia de gremios, asociaciones y escuelas de RR. PP. Muchas empresas en el Perú no consideraron negativa la presencia de otros profesionales (del campo del derecho, mercadotecnia, administración, entre otros) e incluso personas sin ninguna formación superior, quienes convirtieron las Relaciones Públicas en una mera unidad encargada de las ceremonias y eventos protocolares. En todo caso, mediante la decidida intervención de especialistas, académicos y centros de estudios se pudo remediar dicho panorama ${ }^{4}$.

3 Arceo Vacas (1999: 32) es más severo al exponer lo siguiente: "Parece claro que esa parte numéricamente importante de profesionales, la de los aficionados sin voluntad para instruirse debidamente, está causando un gran daño a las Relaciones Públicas. Por añadidura, este conjunto de individuos suele asimismo entender que las RR. PP. se traducen fundamentalmente en conexiones con los medios de comunicación de masas (colocando noticias, etc.). Y entre las increíbles lagunas de este segmento profesional, está la de no conocer cómo ha de hacerse una investigación motivacional del público para después intentar influir precisamente en la imagen (si es el caso) que ese público tiene de la entidad en cuestión”.

4 Con la finalidad de combatir la improvisación y el déficit de conocimientos en torno a las Relaciones Públicas en nuestro país, la Escuela de Ciencias de la Comunicación de la USMP incluyó en sus programas de pregrado materias referidas a las Relaciones Públicas para luego ofrecerlos en los estudios de posgrado: maestría (1996) y doctorado (2005). Esta iniciativa del Decano de la Facultad de Ciencias de la Comunicación, Turismo y Hotelería, Dr. Johan Leuridan Huys, fue posteriormente apoyada por el Gobierno peruano, brindando a las RR. PP. un estatuto oficial, mediante el Decreto Supremo N 021-2004-ED. 
En la actualidad, se cuenta con un gremio creado en el 2005 ("Colegio Profesional de Relacionistas Públicos del Perú”), el cual coincidió paralelamente con la llegada de reconocidas agencias y consultoras de RR. PP. transnacionales, tales como Burston Masteller, Edelman, Llorente \& Cuenca, Pacific Comunicación Estratégica, Corporación Pro Comunicaciones, entre otras ${ }^{5}$. Con la debida acreditación y sustento académico, esta profesión ha logrado consolidarse como una de las más solicitadas en la carrera de Comunicaciones.

Asimismo, gracias a ese paso, las RR.PP. ya no se limitan a "fabricar" imágenes atractivas de las corporaciones y difundirlas arbitrariamente a las diferentes audiencias: los relacionistas de esta década no sólo conocen la necesidad e importancia de planificar las actividades que se organizan, sino que están formados para emplear los instrumentos de medición de las campañas, la metodología para evaluar las mismas y el manejo de las NTIC para poder difundir los mensajes (mediante canales alternativos y cotidianos), aprovechando en sondear las tendencias de opinión de los públicos.

Estos cambios en la praxis de las Relaciones Públicas se deben, en cierta medida, a la innovación y producción de teoría académica en las últimas décadas, enmarcada en el concepto de los “sujetos de las RR. PP.”, desarrollada por Noguero (1999), el cual ayudó a distribuir eficientemente las labores comunicacionales dentro de las organizaciones ${ }^{6}$. El mencionado autor identifica tres tipos de sujetos que interactúan entre sí.

El primer grupo ("sujetos promotores”) estaría compuesto de "cualquier persona física, sea cual fuera su calidad, sexo y condición", así como "cualquier organización en el sentido sociológico in extenso, tanto en el área de la administración pública como de la privada, organizaciones lucrativas como las empresas u organizaciones sin ánimo de lucro non profit organizations, asociaciones cívicas, profesionales, fundaciones, etc.” (Noguero, 1999: 468).

Los "sujetos ejecutores" serían todos aquellos que centran sus actividades en la preparación profesional y el desarrollo de conocimientos útiles para las Relaciones Públicas. Pueden ser los propios relacionistas que trabajan dentro de las organizaciones o profesionales y asesores provenientes de gabinetes y agencias de RR. PP. externas. Se pueden determinar sus cometidos "mediante las contratos profesionales que se realizan entre los sujetos promotores y sujetos ejecutores" (Noguero, 1999: 468).

5 La instalación de áreas de Relaciones Públicas en los sectores públicos ha sido tan extensiva a lo largo de la última década, que se eligió el 18 de junio como el "Día del Relacionista Público Peruano". La preponderancia de esta actividad ha sido retribuida con la organización del XIX Public Relations World Congress del IPRA, desarrollado en Lima en junio de 2010.

6 Como se verá más adelante, con la identificación de los sujetos de las RR. PP., los cuatro modelos de Grunig alcanzan un mayor grado de concreción, ayudando a analizar tanto la dimensión académica como práctica de las RR. PP. En el caso académico, los estudiantes de las Facultades de Ciencias de la Comunicación serían los sujetos receptores; las universidades e institutos serían las organizaciones ("sujetos promotores") y sus profesores (que casi siempre son relacionistas públicos), los sujetos ejecutores. 
Figura 2: sujetos de las Relaciones Públicas.

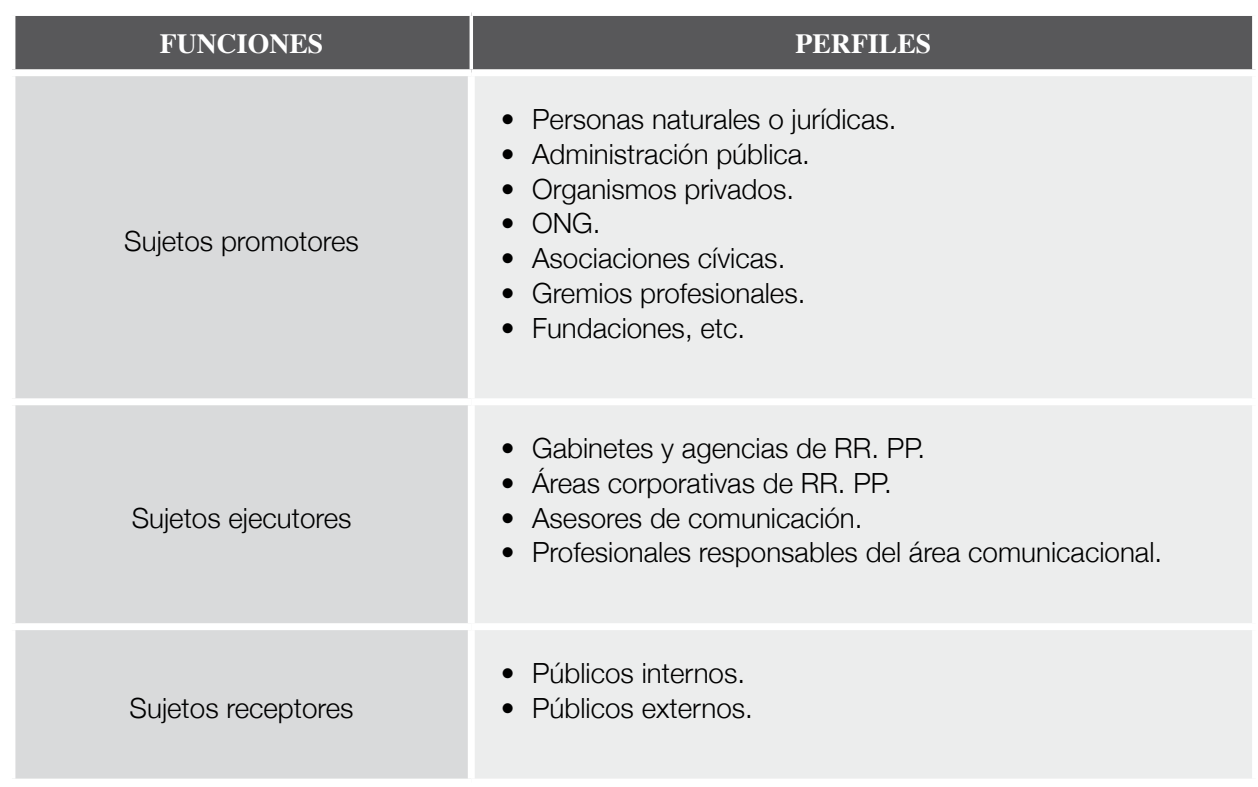

Fuente: elaboración propia basada en Noguero.

Los "sujetos receptores" estarían dispuestos en dos grandes bloques: "los públicos internos, que a su vez se estructura su clasificación de acuerdo con el tipo de organización específica; y los públicos externos que, en no pocas ocasiones, son concurrentes con las de otras organizaciones o instituciones" (Noguero, 1999: 469).

La impronta de Grunig (2000: 104) en el desarrollo de esta disciplina comunicacional ha sido fundamental, sobre todo al plantear los "cuatro modelos de RR. PP." que ilustran (de forma secuencial) su evolución y modificaciones procedimentales a lo largo del tiempo. El paradigma primigenio ("modelo de agente de prensa" o publicity) tendría como objetivo efectuar propaganda: la naturaleza comunicacional es de un flujo unidireccional "en el que se dice la verdad siempre y cuando beneficie a la organización para la que se trabaja".

Asimismo, el tiempo de comunicación que subyace en él es el de "fuente-receptor". La investigación está ausente en este modelo, ya que tan sólo toma en cuenta el número de personas que asiste a un evento o el número de notas de prensa que se emiten mensualmente. Sus procedimientos son muy similares a la de promoción de productos. Esta característica lo enlaza con el "modelo de información pública", que se centra en la difusión de información, mediante una comunicación unidireccional (fuente-receptor). No se destaca por sus diagnósticos o sus investigaciones.

El "modelo asimétrico bidireccional" implicó un considerable avance dentro de las Relaciones Públicas, al incluir los instrumentos de persuasión y evaluación en el proceso de elaborar campañas comunicacionales, así como el monitoreo permanente de los públicos. 
En virtud a esta metodología, la comunicación resultante es de "doble flujo", es decir, bidireccional. Pese a la retroalimentación (en cuanto a los contenidos de los mensajes) la comunicación generada es asimétrica, consiguiéndose efectos "desequilibrados" en los públicos que se veían manipulados por las intenciones del relacionista (Grunig, 2000: 104).

Por último, el "modelo simétrico bidireccional" se basa en el entendimiento muto entre la organización y sus públicos, sean estos internos o externos. El flujo de la información es bidireccional y sus efectos son equilibrados. Por tanto, la naturaleza de la investigación que se lleva a cabo consiste en la evaluación de las comprensiones mutuas. De acuerdo con Xifra (ápud Grunig, 2000: 29-39) este paradigma parte "de la naturaleza contractual de relación existente entre el profesional y la organiza a la que representa. Es más realista, en el sentido de contemplar el hecho de que los objetivos de las RR. PP. han de coincidir con los de la misión de la organización, antes que con los del público".

Si se analizan los cuatro modelos expuestos, se infiere que estos guardan cierto parecido entre sí: los modelos de "agente de prensa" e "información pública" comparten un carácter unidireccional. Resulta una idealización teórica afirmar que jamán evalúan las tendencias de la opinión pública. En realidad, el relacionista (como parte de la sociedad) siempre evalúa lo que acontece en su entorno, aún cuando no sea de manera sistemática.

El segundo modelo se asemeja al tercero ya que ambos son asimétricos, aunque se diferencian por la sistematización de la investigación y el flujo de la comunicación. El tercer modelo, por su parte, comparte con el cuarto el carácter bidireccional en el flujo de la información y la sistematización en lo que a investigación se refiere.

Cabe destacar que de este cuarto modelo se derivan los demás: a) si se reduce la simetría que hay en el cuarto, se obtiene el tercer modelo; b) si se suprime la bidireccionalidad, se obtiene el segundo modelo; c) Si se propugna que la verdad de los mensajes sea algo adjetivo, estaremos ante el primero modelo.

Figura 3: modelos de Relaciones Públicas.
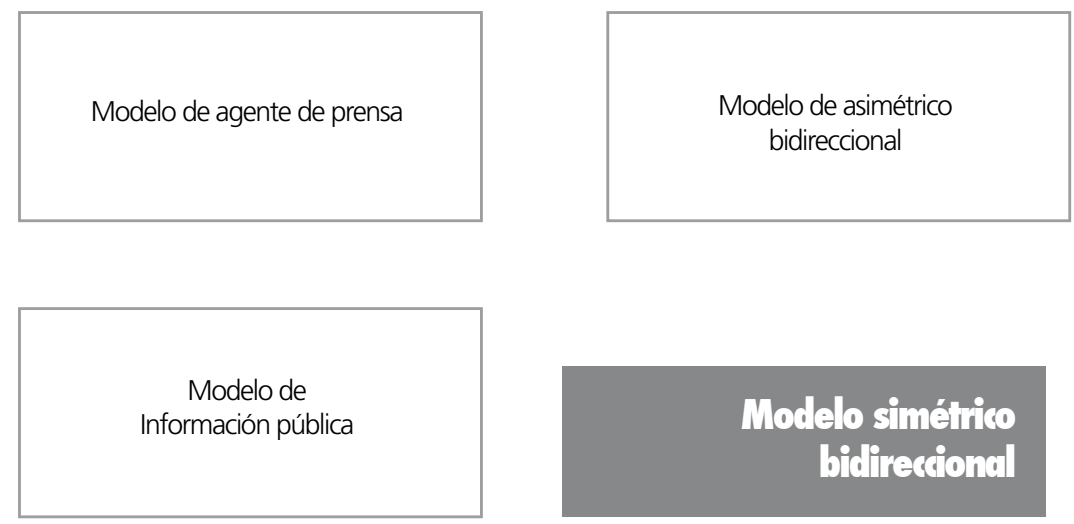

Fuente: elaboración propia, basada en Grunig. 
Por ese motivo, el cuarto modelo es útil para analizar las Relaciones Públicas. Al respecto, Grunig y Hunt (2000: 103) sostienen que estas "son la comunicación e interpretación de ideas e información a los públicos de una institución; la comunicación e interpretación de información, ideas y opiniones de esos públicos a la institución en un esfuerzo por conseguir un ajuste armónico entre ambos".

Con esta concepción, las Relaciones Públicas contemporáneas dejan de ser áreas decorativas dentro del organigrama corporativo (prescindibles ante cualquier corte presupuestal) y sus ejecutores abandonan la improvisación y la mera intuición con la finalidad de asumir responsabilidades más serias, que trasciendan el ámbito primario de la empresa.

\section{Prácticas innovadoras: apertura y adaptabilidad}

La globalización económica ha complejizado los procesos sociales que se desarrollan en nuestro país. Este fenómeno también ha incidido en el comportamiento y la cultura de las organizaciones, sobre todo las dedicadas a la minería y actividades extractivas. En ese contexto, las Relaciones Públicas se establecen como una herramienta comunicacional que ayuda a medir y analizar cuantitativamente la percepción de los stakeholders (grupos sensibles al desenvolvimiento de las corporaciones), previniéndose así crisis sociales y optimizándose los canales de retroalimentación (feedback) entre la empresa y la ciudadanía.

La articulación y mantenimiento de un entorno público favorable, así como las alianzas simbióticas que se podrían establecer, son producto de los programas de responsabilidad social corporativa (RSC). Aplicados en casos específicos (que tienen generalmente como punto de partida el contexto minero) estos planes están orientados hacia la mejora de la calidad de vida de las comunidades y poblados adyacentes a la extracción.

Por ese motivo, resulta importante estudiar los aportes estratégicos comunicacionales que ofrece la RSC, sobre todo en un contexto como el peruano, donde existe una considerable cantidad de corporaciones mineras, las cuales tienen que establecer constante contacto con grupos humanos de diferentes idiosincrasias y cosmovisiones.

El desenvolvimiento empresarial, dentro de contextos complejos y conflictos, ha obligado a las Relaciones Públicas a establecer estrategias que promuevan plataformas comunicativas abiertas al diálogo, la tolerancia y el consenso. En ese sentido, el sector minero tiene en su agenda impulsar no sólo programas filantrópicos o campañas "de imagen”, sino proyectos ambiciosos de desarrollo, que impulse la construcción de infraestructura y el bienestar social de las comunidades adyacentes a los yacimientos.

Así, la responsabilidad social aplicada a la problemática minera debe estar encaminada a impulsar el desarrollo sostenible, la formación de un empresariado líder, programas sociales inclusivos y una comunicación aliada al real conocimiento de la zona, sin olvidar aspectos competitivos y de excelencia corporativa. Con esta nueva configuración y perspectivas, las Relaciones Públicas están abocadas a la solución de conflictos (entre lo que implica los intereses mineros y sociales) y a establecer puntos de encuentro, diálogo y 
consenso entre las corporaciones y las comunidades. De esta forma, se crearían "áreas de influencia" minera, productivas y respetuosas con el medio ambiente y las colectividades que las acogen.

El planeamiento estratégico en Relaciones Públicas es un segundo aspecto que resulta fundamental, ya que diversas variables (opinión pública, esferas políticas, ONG, entorno comunitario) han conformado una serie de problemáticas que ni siquiera el Gobierno central ha podido arbitrar o administrar adecuadamente. Así, el monitoreo y el estudio detallado de los grupos sociales (su cosmovisión e interacción con las instituciones) es una labor obligada y vital para el relacionista, ya que con los resultados obtenidos se podrán diseñar acciones comunicacionales capaces de brindar credibilidad a la imagen y a los mensajes de las corporaciones.

De esta forma, el conocimiento científico (desplegado en los métodos de investigación de los públicos, los climas de opinión y en el diseño adecuado de estrategias comunicacionales) permite al relacionista prevenir o solucionar los conflictos que puedan surgir entre las organizaciones y sus públicos, salvaguardando la cohesión y la confianza: el futuro de las Relaciones Públicas apunta a conformar una filosofía empresarial, abocada al conocimiento pleno de sus públicos y al adecuado desenvolvimiento social de las corporaciones.

El rol concertador y mediador del relacionista que pueda proyectar hacia las comunidades acrecienta la confianza y el compromiso del empresariado con la ciudadanía en general, nutriendo la sensación de integridad y buena voluntad de las inversiones (tanto nacionales como extranjeras) que buscan aumentar el empleo, mantener la estabilidad macroeconómica y asegurar el progreso del Perú.

Un tercer punto a destacar es la incidencia de las NTIC dentro de la labor del relacionista público: los formatos digitales y portátiles (smartphones, tablets, laptops, etc.) están revolucionando la comunicación dentro de las corporaciones, modificando gradualmente la metodología tradicional de las RR. PP. Los alcances de las redes sociales virtuales (Twitter, Facebook, entre otros) adquieren un mayor protagonismo dentro del proceso de elaboración y coordinación de los planes de comunicación estratégicos, así como de la evaluación de dichos programas y del monitoreo de los públicos.

En líneas generales, se debe rescatar la función estratégica de las Relaciones Públicas a la hora de acercarse y conocer a los stakeholders (administración de controversias, planes de crisis). Además de prevenir y solucionar posibles conflictos sociales, se asegura el bienestar comunitario y se reafirma la confianza hacia las actividades corporativas.

Si bien se ha experimentado un boom en la producción de mensajes publicitarios (un ejemplo de ello es la elaboración y difusión exitosa de la denominada "marca Perú"), las empresas requieren otros tipos de canales para comunicar sus valores y cualidades diferenciales: el público es más exigente y conoce la competencia (vía Internet). Por ello, las RR. PP. no deben estar orientadas exclusivamente a los públicos externos, sino también a los internos; se debe considerar al stakeholder como el ente esencial de toda campaña comunicacional, porque en él se reflejará el éxito de la acción comunicativa. 


\section{Incidencia en las decisiones de la alta gerencia}

Las Relaciones Públicas contemporáneas apuntan a conformar una filosofía empresarial, dirigida al conocimiento pleno de sus públicos y al adecuado desenvolvimiento social de las corporaciones. Su rol concertador y mediador con las comunidades acrecienta la confianza y el compromiso del empresariado con la ciudadanía en general, nutriendo la sensación de integridad y buena voluntad de las inversiones (tanto nacionales como extranjeras) que buscan aumentar el empleo, mantener la estabilidad macroeconómica y asegurar el progreso del Perú.

Dentro de este contexto dinámico y estimulante, las Relaciones Públicas se conforman como una parte orgánica de la alta dirección de las organizaciones. La integración del relacionista con las principales decisiones corporativas permite una estructuración más concertada de las estrategias comunicacionales, así como un acercamiento más real entre la gerencia y los stakeholders, lo cual se traduciría en alianzas más comprometidas y productivas con las diversas comunidades. En la actualidad, aquellos relacionistas que se encuentran alejados de las líneas ejecutivas de las empresas cumplen una labor menos profunda.

El relacionista público del siglo XXI es un profesional que participa ampliamente en el desarrollo de los objetivos generales de la empresa, con la libre prerrogativa de proponer programas comunicacionales a la alta dirección, gestionando su presupuesto y ejecutándolo. Sólo así podrá enfrentar, con efectividad, situaciones de crisis y desinformación que podrían ser desfavorables para la corporación.

En esa línea, Wilcox,Autt,Agee y Cameron(2001:94) subrayan el carácter multidisciplinario de los relacionistas, quienes "deben tener la mejor formación posible en economía. Una vez que hayan iniciado su carrera profesional, tendrán que analizar los aspectos financieros relacionados con el empresario que les contrata o sus clientes. Cada vez más, la actividad de Relaciones Públicas consiste en distribuir e interpretar información financiera".

El empresariado nacional está comprendiendo que las Relaciones Públicas no son un área prescindible y “decorativa”. Si bien comenzó como una herramienta aparentemente secundaria, ahora posee una posición vital, con la responsabilidad de emprender investigaciones cuantitativas a los públicos, evaluar el impacto de programas ejecutados anteriormente y generar proyectos acordes con las exigencias del entorno o coyuntura determinada.

\section{Conclusiones}

Resulta necesario redimensionar las Relaciones Públicas (así como las problemáticas y coyunturas que la rodean) desde varios aspectos: uno de ellos correspondería a la realidad de la actividad empresarial del país (sobre todo la extractiva) que vaya más allá de los programas de Responsabilidad Social y se compenetren (a largo plazo) con el contexto de las comunidades y grupos humanos circundantes a la actividad minera. Sólo una actitud responsable ayudará a clarificar el panorama y no cerner más sombras e incertidumbre en él. 
El segundo aspecto a ser considerado es la evolución misma de las Ciencias de la Comunicación y, por ende, de las Relaciones Públicas frente a este escenario. Es tarea vital examinar esta disciplina (impartida en las universidades) y su aplicación (directa o indirecta, paradigmática o imperfecta) en el campo laboral, que inciden en el desempeño de las diferentes corporaciones.

Como tercer punto, subrayar el valor pedagógico y cívico de las Relaciones Públicas, tendiente a enlazar intereses intersectoriales que ayudan a mejorar la praxis empresarial, académica y deontológica. Con ello, se demostraría que las RR. PP. y la pedagogía comparten el fin educativo de transmitir información de manera eficaz, oportuna y veraz (abandonándose así la aparente naturaleza "lobbista" y maquiavélica que ha empañado a esta disciplina) con capacidad de retroalimentarse y adquirir una presencia más tolerante, empática y cercana a los problemas del país ${ }^{7}$.

No hay duda que el modelo "simétrico-bidireccional" se adecua al ámbito pedagógico: el relacionista (en su rol propiamente dicho o como docente) vincula a los alumnos o públicos (según sea el caso) con los contenidos que la universidad u organización quiere que se le brinde de acuerdo con los planes de estudio y empresariales. De esta manera, el relacionista siempre está realizando una labor pedagógica, ya sea académica o laboralmente. Su función es transmitir mensajes que permitan cambios en la conducta u opinión de los públicos.

Si bien el Perú está experimentando un crecimiento económico sostenido (pese a las alarmas financieras que provienen del exterior), resulta vital que las empresas apliquen las estrategias de RR. PP. a fin de prevenir posibles retracciones del mercado y de cambios drásticos en la percepción pública, que pueden degenerar en escenarios conflictivos sin atisbos de resolución.

Las Relaciones Públicas no componen el remedio mágico absoluto para solucionar todos los problemas de las corporaciones y del país en general. Los programas de RSC no convierten necesariamente a las empresas en modélicos "ciudadanos" con una buena imagen. Conocer los parámetros y alcances reales de las RR. PP. resulta clave, sobre todo en un contexto complejo y multicultural como el peruano.

La práctica de las RR. PP. ofrece alternativas creativas a las empresas para su mejora y crecimiento. En ese sentido, la aplicación de sus principios no debe restringirse a las grandes corporaciones multinacionales: la diversificación del mercado nacional ha dado cabido a pujantes entidades empresariales, las cuales tienen una oportunidad imperdible de hacer extensiva esta disciplina comunicacional en el próximo lustro.

7 Esta reflexión trae a colación la función social de las Relaciones Públicas, incluida en la Declaración de principios de la CONFIARP: "La gestión relacionística tiene la responsabilidad de propiciar condiciones aptas para la interrelación y la intercomunicación efectiva de todos los sectores que constituyen al conjunto social, atendiendo para ello la justa expresión de los intereses y respetando el pluralismo en las ideas, siempre que estas sean compatibles con el bien común, el libre albedrío dentro del marco de la ley y las lógicas aspiraciones de progreso y bienestar". 


\section{Fuentes consultadas}

- AA. VV. (2010). Gerencia social. Diseño, monitoreo y evaluación de proyectos sociales. Lima: Universidad del Pacífico.

- Arceo Vacas, J. (ed.) (1999). Tratado de Publicidad y Relaciones Públicas. Madrid: ICIE.

- Asociación de Empresas Consultoras en Relaciones Públicas y Comunicación ADECEC (2002). La comunicación y Relaciones Públicas en España. Radiografía de un sector. Barcelona: Pirámide.

- Caravedo, B. (1998). El impacto social de las empresas mineras en el Perú. Lima: Instituto de Estudios Energéticos Mineros.

- Del Castillo, E. y Yamada, G. (2010). Responsabilidad social y buen clima laboral: una fórmula ganadora. Lima: Universidad del Pacífico.

- Grunig, J. E. y Hunt, T. (2000). Dirección de Relaciones Públicas. Barcelona: Gestión 2000.

- Guth, D. W. y Marsh, C. (2006). Public Relations. A Values-driven approach. Boston: Pearson Education.

- Harlow, R. (1976). "Building a Public Relation Definition”. Public Relations Review, núm. 4, pp. 24-30.

- Harrison, S. (2002). Relaciones Públicas. Una introducción. Madrid: Thomson.

- Louffat, E.; Hernández, V.; Ingar, R.; Mavila, L. y Vento, C. (2008). Cultura organizacional en estructuras en red. Lima: Universidad ESAN.

- Martín Martín, F.

_(2010). Comunicación empresarial e institucional. Madrid: Universitas.

_(2004). Diccionario de comunicación corporativa e institucional y Relaciones Públicas. Madrid: Fragua.

- Noguero i Grau, Antoni (1999). "Características principales de la actividad tipificada como industria de Relaciones Públicas en España: sujetos promotores y sujetos ejecutores", pp. 467-508. En Arceo Vacas, J. (ed.). Tratado de Publicidad y Relaciones Públicas. Madrid: ICIE.

- Sanborn, C. y Portocarrero, F. (2010). Filantropía y cambio social en América Latina. Lima: Universidad del Pacífico.

- Schwalb, M. (2010). Experiencias exitosas de Responsabilidad Social Empresarial. Lima: Universidad del Pacífico.

- Schwalb, M. y Malca, O. (2010). Responsabilidad social: fundamentos para la competitividad empresarial y el desarrollo sostenible. Lima: Universidad del Pacífico.

- Schwalb, M.; García, E. y Soldevilla, V. (2010). Buenas prácticas peruanas de Responsabilidad social empresarial. Lima: Universidad del Pacífico.

- Solano Cornejo, D. (2009). Responsabilidad social: estrategias sostenibles para el desarrollo y la competitividad. Lima: Universidad ESAN. 
- Solano Fleta, L. (1999). Tratado de Relaciones Públicas. Barcelona: Gestión 2000.

- Wilcox, D.; Ault, P.; Agee, W. y Cameron, G. (2001). Relaciones Públicas. Estrategias y tácticas. Madrid: Pearson Educación. 